\title{
li. USING AUTO-PHOTOGRAPHY TO EXPLORE YOUNG PEOPLE'S BELONGING AND EXCLUSION IN URBAN SPACES IN ACCRA, GHANA.
}

\section{Kristijn van Riel, Ashraf M. Salama}

\begin{abstract}
This paper examines young people's 'lived' experience of urban spaces in Accra, the capital of Ghana, by focusing on the use of auto-photography as an appropriate method for this investigation. Accra has a very young population and low rates of employment among the young people, demographics that are often associated with societal instability and increased risk of civil conflict. Research into African youth and the urban spaces they occupy is scarce and involves real challenges, but it is necessary and urgent due to various issues of exclusion and identity. This paper reports part of a larger phenomenological study on the spatial exclusion of youth in Accra's urban spaces. The theoretical framework builds on Lefebvrian dialectics of space and focuses on how notions of belonging and exclusion are reflected in the mode of 'lived space'. The fieldwork was completed on a small sample of young people in two distinct neighborhoods of Accra. In essence, the focus of the paper is on the urban spaces occupied by young people and on the utility of the participatory research tool adopted, auto-photography. In this context, the tool is less intrusive than direct observation and therefore well equipped to allow an 'insider' view into personal experiences and perceptions of place that are otherwise difficult to access and study. The paper concludes with a call for urban professionals and decision makers to produce inclusive urban environments that cater for all while allowing for differences and belonging to co-exist.
\end{abstract}

Keywords: Accra, Youth, Exclusion, Belonging, Auto-photography.

\section{AFRICAN CITIES AND YOUTH}

Sub Saharan Africa continues to face substantial challenges of economic and social development. Many countries in this region have suffered problematic and often violent transitions from colonial pasts to sovereign states, and many currently struggle to benefit from processes of globalization. According to Harvey (2003), widening class divisions, driven by the free market policies of global capitalism, are largely responsible for the social segmentation of cities we see throughout the world today. The social effects of these inequalities are often amplified if they overlap with other social categories of difference, such as age, gender, race, culture or religion. Additionally, contrasts are further magnified as administrations often lack the capacity or resources to manage the pace of urbanization and migration, contributing to further economic and social polarization of societies (COHEN, 2006).

Many cities in the Global South currently experience a youth bulge; an overrepresentation of young people in their demographic composition. This demographic profile, while it has the potential to stimulate economic growth when coupled with ample opportunities and conducive socio-economic conditions (ARNOT and SWARTZ, 2012), it has been asso- ciated with societal instability and increased risk for civic unrest, particularly when associated with deprivation and social exclusion (BEEHNER, 2007; URDAL, $2011)$. A visible feature of Accra's urban landscape is the omnipresence of young people, often sitting idle or just 'hanging about' the city's open spaces (as observed by for instance LANGEVANG, 2008a).

Young Africans experience forms of marginalization, often being excluded from spaces of politics, labor, education and leisure (DIOUF, 2003). Their marginalization must be understood as a link to a larger and dramatic shift of the African identity over the past decades, following the intensification of the economic and financial crisis, the erratic trajectory of democratization and political fissures that appeared at the end of the 1980s. The subsequent invasion of public and domestic spheres by young people has profoundly startled African societies. As a response to their exclusion, young people often resort to the production of new forms of social space that explicitly demonstrate their difference, claiming spaces abandoned by the establishment, on the margins of society and outside of dominant cultures (DIOUF, 2003; DE BOECK and HONWANA, 2005; LANGEVANG, 2008a). Simultaneously, parks, squares and other 'dedicated' public spaces are rare in Accra, and are often designed and managed in an exclusionary man- 
ner, defending them from 'unwanted' visitors such as street hawkers, homeless people or indeed, loitering youth. The street therefore is an important arena for many young people to affirm, negotiate and challenge their identities (GOUGH and FRANCH, 2005; WINTON, 2005). Public space itself has challenged theorization (KOHN, 2004), particularly in African cities, largely because they have long been almost completely absent from urban literature. Several notable scholars such as SIMONE, 2003; ROBINSON, 2006; PIETERSE, 2011 have urged for urban research to come to terms with, and start to take seriously, contemporary African urbanisms in all their diversity.

In most cities, young people are often unaccounted for in - if not deliberately omitted from political decision making processes, despite that these processes affect their lives as much as any citizen (FREEMAN and TRANTER, 201 1). Skelton and Gough (2013) have noticed that, despite their visible presence in the urban landscape, youth has long been largely overlooked by urban research. This omission in the literature reflects, and arguably reproduces, their exclusion in the urban realm. A range of authors (e.g. LANGEVANG, 2008b; LANGEVANG and GOUGH, 2009; HOPKINS, 2010; SKELTON and GOUGH, 2013) advocate the urgent and important project of recognizing and enabling the agency of young people in theory and practice, not in spite of, but because they behave differently in relation to the city, they are an important part of cities' characteristic diversity and they play a significant role in the production and consumption of urban culture and identity (SKELTON and GOUGH, 2013). This paper responds to urgent calls for research on belonging, youth and public space in Accra as an example for demonstration.

\section{PRODUCTION OF SPACE, BELONGING AND EXCLUSION}

Reporting on a part of a larger phenomenological study involving the implementation of various investigation mechanisms, this paper captures key issues of spatial justice that pertain to youth in Accra's public realm. A theoretical framework is established based on Lefebvrian dialectics of space, with a focus on how notions of belonging and exclusion are reflected in the mode of 'lived space'. At the core of Henri Lefebvre's urban theory lies the concept of social space, and the "three moments of social space" which exist in dialectic, yet hierarchical, relation to one another, each contributing in important ways to shaping the landscape (LEFEBVRE, 1991). He calls these moments: the conceived, the perceived, and the lived space.

The highest and most abstract level of space, 'conceived space', is a discursive and strategic space (LEFEBVRE, 1991; ZHANG, 2006). It is in this ideological space that hegemonic power is situated, and where urban governance operates (WIEDMANN et al., 2014). The second level, 'perceived space', is an empirical, material space, made up of flows of capital, labor, and information. It is the space of collective agency, in which conceived and lived spaces are interpreted and reduced to images, depictions and plans by architects and planners, but also by corporations and industries. It is where forces of capitalism reign supreme and the main space of production (HARVEY, 1990; ZHANG, 2006). The third level of space, and the one that the present investigation is concerned with, the 'lived space', is a deeply subjective, humanized and bodily space, and consists of the "inner structure of space, as it appears concretely to man in his experience" (BOLLNOW, 1961, p. 31). It is the space of users, meaning, affect, emotion, and imagination (LEFEBVRE, 1991; ELDEN, 2004; ZHANG, 2006). The important concept of place is generally recognized as located and grounded in the lived mode of space. Following Wiedmann et al. (2014), it can be argued that social justice and the associated processes of inclusion/exclusion can best be understood in terms of processes of identification - or rather belonging - between individuals, collectives and places, by investigating closely the lived dimensions of space.

Based on YUVAL-DAVIS (2006) and FENSTER (2005), ANTONSICH (2010) identifies two interdependent dimensions of belonging. The first dimension treats belonging as a subjective, personal and intimate attachment to place. This dimension is firmly rooted in the everyday (FENSTER, 2005) and can be interpreted as a central aspect of Lefebvre's lived mode of space. The second dimension deals with belonging as a discursive resource that 'constructs, claims, justifies and resists forms of socio-spatial inclusion/exclusion' (ANTONSICH, 2010, p. 4). This is the politics of belonging, aptly described by John Crowley (1999, p. 30) as 'the dirty work of boundary maintenance,' boundaries that delineate a community of belonging, their maintenance encompasses defining what behavior is or which characteristics are appropriate for membership in this community and its associated territory (TRUDEAU, 2006). Claiming who is allowed to belong and who is excluded, in order to monopolize resources and retain power, this process of social closure, is a constituent part of the conceived mode of space (SOJA, 1996). Antonsich (2010) emphasizes that the sense of belonging can be embodied and affectively felt, but it is always socially constructed and thus never isolated from power dynamics in place.

The study of the affective dimension of belonging, or the sensation of feeling at home in place, often poised as the counter-pole of exclusion (TRUDEAU, 2006), reaches back to the phenomenological tradition of humanistic geographers (RELPH, 1976; TUAN, 1977). Home, in this sense, is not restricted to the physical domestic space, but rather 
refers to the symbolic idea of Heimat; a familiar space, a safe zone of emotional attachment and agreement, a place where one feels protected and at ease. This tradition recognizes both notions of place and mobility as fundamental to the human project of identity formation (EASTHOPE, 2009). PfaffCzarnecka (2011) notes that the notion of belonging allows for the conceptualization of more dynamic modes of collectivity that are based on shared experience, knowledge and meaning, thereby going beyond often dichotomous signifiers of identity. Belonging can therefore be characterized as a fluid, multi-faceted construct, a process subject to continuous social and spatial transformations, involving simultaneous attachments to different places and collectives, often evoking feelings of in-betweenness or hybridity (PFAFF-CZARNECKA, 2011; LÄHDESMÄKI et al., 2016). Committing to exposing the multiple forms of belonging and exclusion as manifested in young people's lived, everyday experiences poses the challenge of finding analytical tools that befit the multidimensionality of the concepts.

\section{AUTO-PHOTOGRAPHY AS A WINDOW INTO THE LIVED SPACE}

Scholars have recognized the need to diversify methodological tools that allow the understanding and interpretation of everyday practices, and allow serious investigation into the 'lived space' (LATHAM, 2003; ANDERSON and JONES, 2009). To this end, Auto-photography was identified as a valuable tool. It is a participatory research method that involves the participant operating the camera, rather than the researcher. This method originates from the field of psychology, where it is an established method for looking into issues of individual identity (WORTH, 1964; ZILLER and RORER, 1985). It has been used to provide insider perspective into everyday experiences of specific groups of people, especially marginalized groups such as homeless people, minority communities, or urban poor. More recently, this method has proven great potential in providing valuable insight into informal modes of place-making and place meaning in a phenomenological inquiry by Melanie Lombard $(2013,2014)$. She has demonstrated that it is particularly well equipped for use with marginalized groups, exactly because it has the potential to empower participants, by revealing insider views and narratives of place that challenge and contest dominant representations.

It is imperative to consider important ethical considerations regarding the use of participatory methods with young people in a disadvantaged setting. In order to protect participants' privacy and wellbeing, all names were replaced with pseudonyms and all identifiable people in photographic data were made unrecognizable. In many densely populated areas of Accra, social control tends to be high, therefore chance persists that community members were able to identify participants. The participants were encouraged to share as much as possible of their daily activities, grievances and challenges, but also warned against revealing things that might expose them to social consequences. Additionally, the issue of power relations between the participant and the researcher was fully considered. Post-colonial and feminist critique firmly and correctly advise for extreme caution and reflexive practice when working in a context of vulnerability or marginalization, particularly in a context that involves post-colonial tension. Crucially, building rapport between the researcher and the participant through other activities, clarity and transparency related to the objectives of the research, mutual expectations of the process and future outcomes and benefits for the researcher, were all important factors in implementing this approach.

Reporting on a part of a larger investigation into marginalization of youth, the fieldwork was completed on a small sample of young people between the ages of 18 and 35 in two distinct neighborhoods of Accra. It was conducted utilizing several stages, to increase the likelihood of building rapport with participants where Auto-photography was the final stage with the young participants, after they participated in focus group discussions, cognitive mapping, and informal conversations.

\section{TWO NEIGHBORHOODS OF ACCRA: GA MASHIE AND SABON ZONGO}

Accra, the capital of Ghana, was identified as a platform for exploration and as an important case representing Sub-Saharan African cities; as one of the fastest growing and globalizing cities of the region. In the year 2000, approximately $56 \%$ of Accra's residents were under the age of 25, while formal unemployment among youth was very high (ACCRA METROPOLITAN ASSEMBLY, 2000; YOUTH EMPLOYMENT NETWORK, 2002). Furthermore, as a former capital of the British Gold Coast colony, its urban fabric still demonstrates social segmentation after decades of colonial planning. The British planning actively implemented social and spatial segregation between European, indigenous and migrant populations, which has arguably remained relatively intact. Currently, this has significant consequences on the social fabric, in enduring high levels of inequality, but also for the spatial fabric of the city, in vastly different levels of infrastructure and social services between the different areas. Accra is a highly dynamic and heterogeneous city, with a great deal of exchange and intermingling taking place within and between different neighborhoods. Arguably, however, the oldest indigenous and migrant areas have remained distinct and 

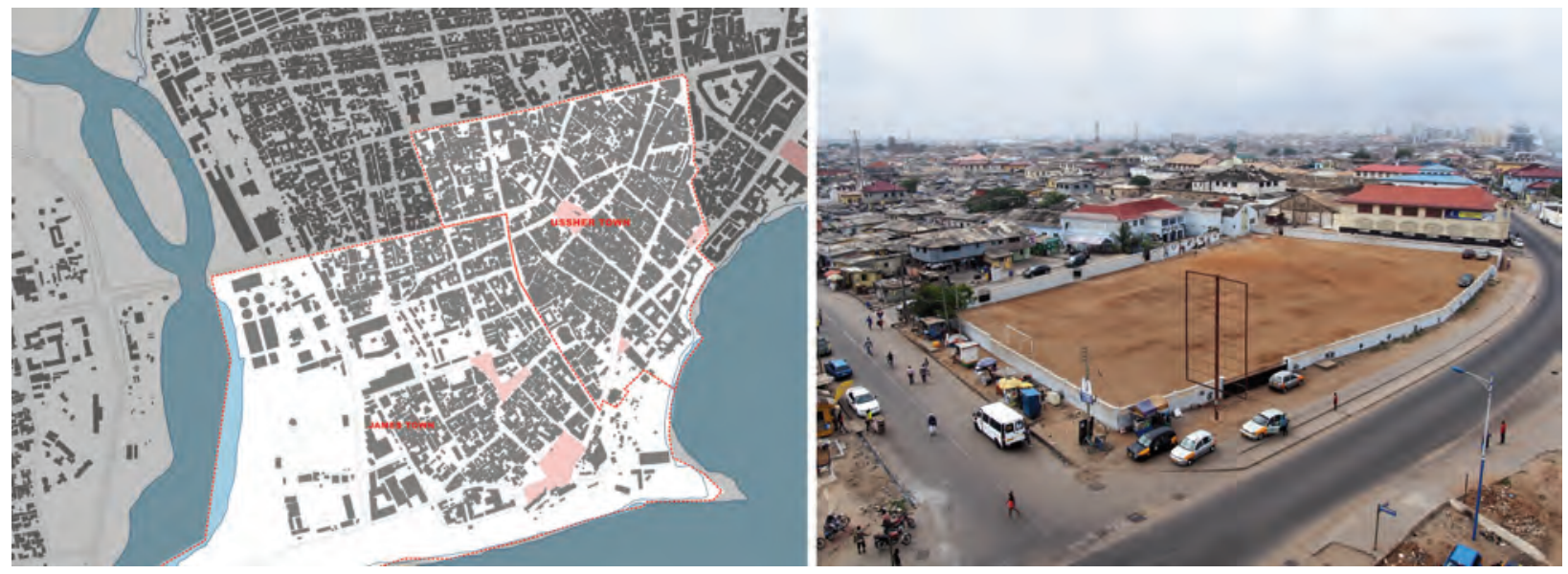

Figure 7. Ga Mashie, with one of the main traditional palaces in the front, seen from the James Town lighthouse. (Source: Authors).

retained their unique cultural characteristics and composition. Two of the oldest neighborhoods of Accra were selected as study areas, Ga Mashie, an indigenous area, and Sabon Zongo, a migrant area. Their distinctiveness serves to illustrate the broad spectrum of urban form and social composition in urban Accra: two examples situated at the extremes of the spatial and social continuum of the city, against which youth's behaviors and perceptions in the public realm are juxtaposed.

In 2010, the Ga Mashie area, or 'Old Accra', is centrally located on the coast, and housed 42,530 people with an average residential density of just fewer than 394 people per hectare. The main religious affiliation is Christianity with 77.8 per cent, the largest share of which are followers of the various charismatic churches (GHANA STATISTICAL SERVICES, 2010). Some of its most prominent features include the fishing activities, the boxing gyms and traditional palaces of the Ga kings - influential local chiefs that control most of the urban land of Accra - scattered throughout the area (Figure 1). The lack of urban development plans for Ga Mashie has allowed this part of the city to dete- riorate and socially degrade, now demonstrating insufficient sanitation, dilapidated infrastructures, rampant over-crowding, and rundown housing (MELARA ARGUELLO et al., 2013). These factors have contributed to halt the influx of migrants into the area (AGYEI-MENSAH and OWUSU, 2010). The Ga people are indigenous to the Accra plains, but outside of the indigenous areas, they are outnumbered in their city by ethnicities from Central and Northern Ghana (AGYEI-MENSAH AND OWUSU, 2010; GHANA STATISTICAL SERVICES, 2010).

Sabon Zongo in 2010 had a population of 27,550 with an average density of 666 residents per hectare, housed on a small area just to the NorthWest of Ring Road (GHANA STATISTICAL SERVICES, 2010). Its main religious affiliation is Islam, with a percentage of 56.6 of its residents ascribing to the Muslim religion, much higher than the average of 11.8 per cent in the Accra area (GHANA STATISTICAL SERVICES, 2010). Zongo means 'stranger area' in Hausa language and is a term used throughout West Africa to denote urban neighborhoods with large migrant populations. Sabon Zongo was the first zongo
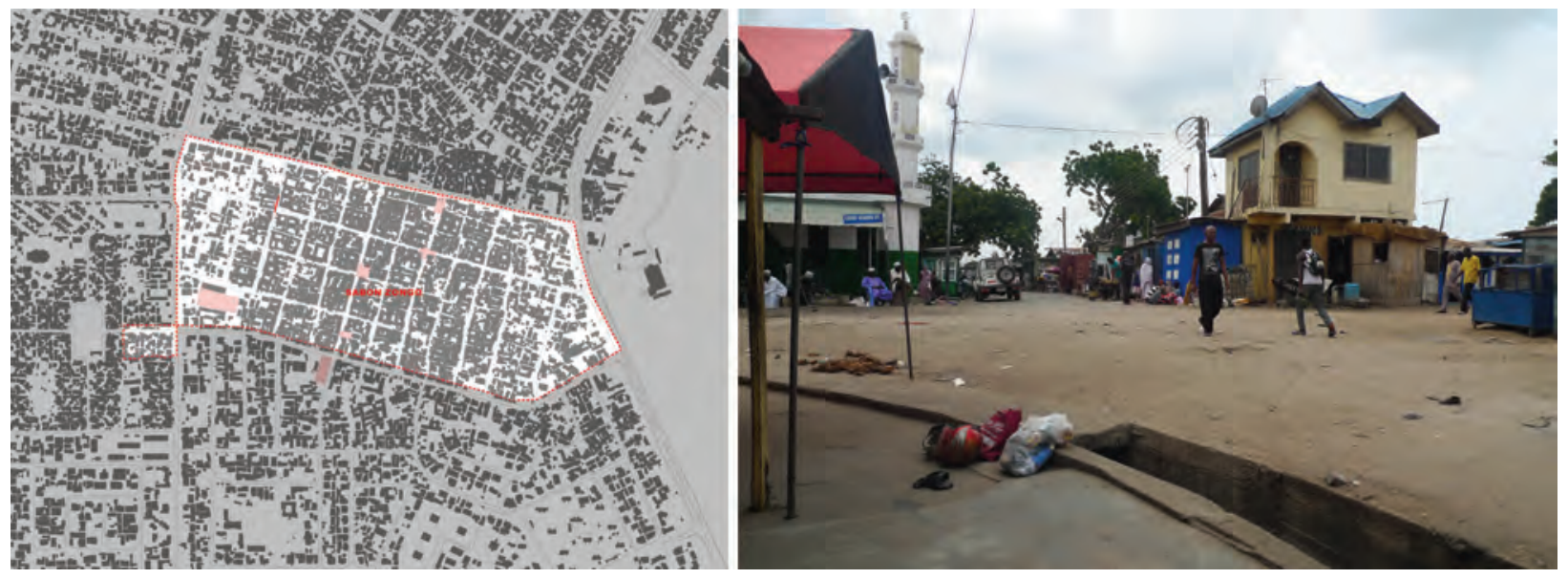

Figure 2. Most of the roads in Sabon Zongo are unpaved, with little automated traffic and small livestock roaming free, contributing to a rural character of the neighborhood. Narrow alleyways puncture the orthogonal street plan and are often used as extensions of the domestic space. (Source: Authors). 
in Accra, established in the first decade of the $20^{\text {th }}$ century by, and deliberately created for, Hausa migrants from Northern Nigeria. Its demographic composition has become more heterogeneous over the decades, to accommodate mostly Muslim migrants of Northern Ghana and other countries, but the dominance of the Hausa culture and linked Muslim orientation in the neighborhood has persisted (PELLOW, 1991). The spaces of Sabon Zongo feel distinctly different from the surrounding areas, more rural in character than most of Accra, its streets are narrow, and slightly disturbed by automated traffic where children and animals roam free through the streets (Figure 2).

\section{SPACE, POWER AND BELONGING IN ACCRA}

Urban places occupied by young people deserve more attention than previously granted in literature. Following the preceding introduction to the neighborhoods, some of the narratives and photographs shed light on the use of place and link it to discourses of belonging. Two themes were identified that highlighted different aspects of the concept of belonging: mobility and place.

\section{Mobility and belonging}

In these dense areas, availability of open spaces is limited. Young men especially tend to spend a significant amount of time in public spaces, as domestic spaces are considered off-bounds for them during the day. Public space is characterized by copresence and diversity, its use reflects temporalities and spatialities that are conditioned by power in place, and hence prone to expressions of uneven power relations. In most of Accra traditional leadership (in Sabon Zongo in close connection with religious leadership) is responsible for managing space on behalf of the community, resolving spatial disputes, and making decisions on the use of space. As in most African societies the social hierarchy ranks elders higher and puts youth in lower positions. These positionalities differentiate open spaces, and the relationships between users and locations in space.

Young people are often (made) acutely aware of their low social ranking evidenced in their narratives and practices. When sharing open spaces with other users, they are frequently seen occupying less desirable locations (near sources of pollution or noise, or using non-shaded spaces, for example). In other cases, youth share open spaces, but within different time-frames. During most of the day, many open spaces are occupied by sellers for commercial purposes, or other users (e.g., school playgrounds, companies' parking lots, as shown in Figure 3). Only in the evenings or at night do these spaces become available for appropriation by youth (Figure 4). Several young people indicated that in the evenings they feel more empowered and freer to go where they want,

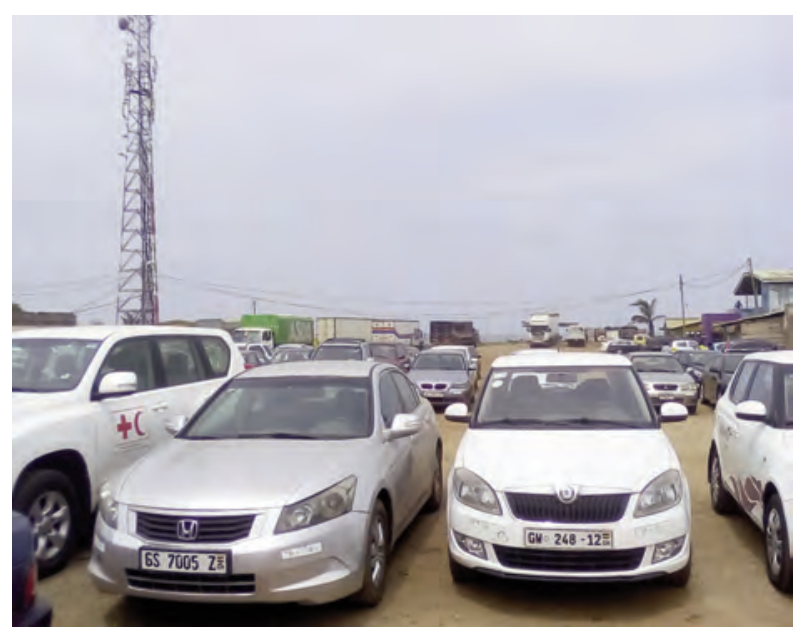

Figure 3. This is a public football field in the evenings, but during the day it serves as a parking lot for a nearby bank. (Source: participant).

because, as one participant said, that is when they "control the street."

Palpably, young people are responding to their marginalization by drawing upon certain fluidity, a tactical adaptiveness of their practices to an unpredictable, uncertain and hostile environment. A situation might require youth to sit in the open, where they can sustain social relationships and build support networks, or to present themselves available to small work opportunities (vital to some livelihood strategies as observed by LANGEVANG, 2008a). However, sometimes avoiding conflict requires rendering themselves invisible in the margins of, or removing themselves entirely from, public space, or moving into spaces outside of the public eye. The narratives reveal a slumbering, sometimes uneasy, mobility; a readiness to pack up and move, to seize an opportunity, or to avoid unwanted interactions or engagement with others.

The daily practices of young people are characterized by this tension between rest and movement, waiting for long hours, yet often alternating between different places and social roles, each presenting opportunities and risks, and altered power positions. On the one hand, it highlights a form of agency, spatial tactics that involve assessing and challenging the constraints of the environment (LANGEVANG and GOUGH, 2009). On the other hand, it is largely because it occurs in unfavorable power geometries, it has a profound impact on the sense of ownership and the production of a sense of belonging in place. The imposed mobility - between different places and different social positions - might mean that youth are producing only transitory connections to the spaces they inhabit and move through, which likely contributes to a sense of exclusion.

\section{Place and belonging}

The photographs and the narratives behind them 


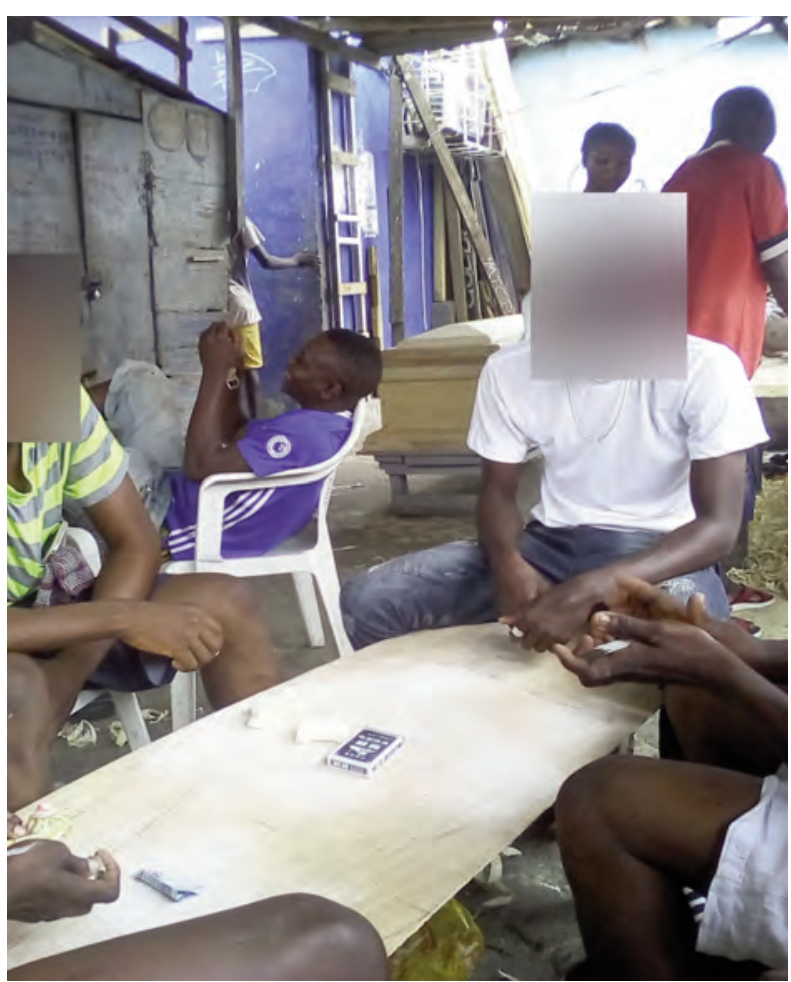

Figure 4. Several young men hanging out at a friend's woodshop. (Source: participant).

exhibit strong connections between participants and aspects of their everyday environment, features that simultaneously challenge, nuance and confirm views of youth as powerless and passive in their marginalization. In Sabon Zongo, photographs that represented a sense of belonging for the youth, places where they felt safe and fully appreciated, almost exclusively showcased places and events that brought young people together with peers and granted membership to a collective based on similar values (Figure 5). For most participants, that was their local mosque and aspects of the Muslim community (Figure 6). One Christian participant also highlighted religion as crucially important to her. However, the absence of a vibrant Christian community, churches or neutral public spaces within the area did reportedly complicate her sense of belonging to the area, as she indicated that she sometimes felt a 'stranger' in her own neighborhood. Virtually all residents in Sabon Zongo have migratory backgrounds and retain a sense of belonging that is partially located outside the boundaries of Accra, or Ghana.

Notably, the ethnic heterogeneity and residential density is high and open spaces are limited within the neighborhood. It is hardly surprising, then, that religion serves for many as the main unifying element; spaces of worship constitute key "public" spaces, vital stages for community building and centers of focus for residents' everyday practices. Consequently, religious leaders have often become influential community leaders, and spaces of worship have become platforms for community politics.

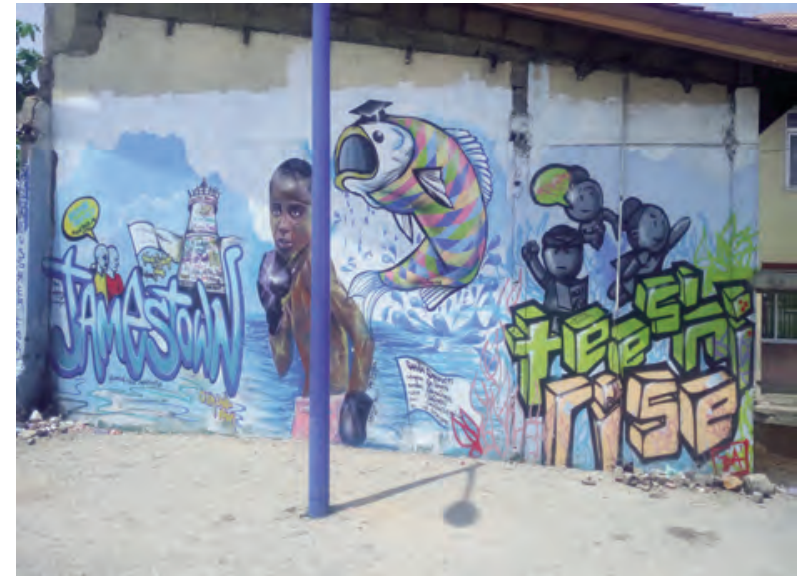

Figure 5. This mural, a remnant of the iconic Chale-Wote art-festival, illustrates some of the most important features for the inhabitants of Ga Mashie: education, boxing, fishing and the lighthouse. (Source: participant).

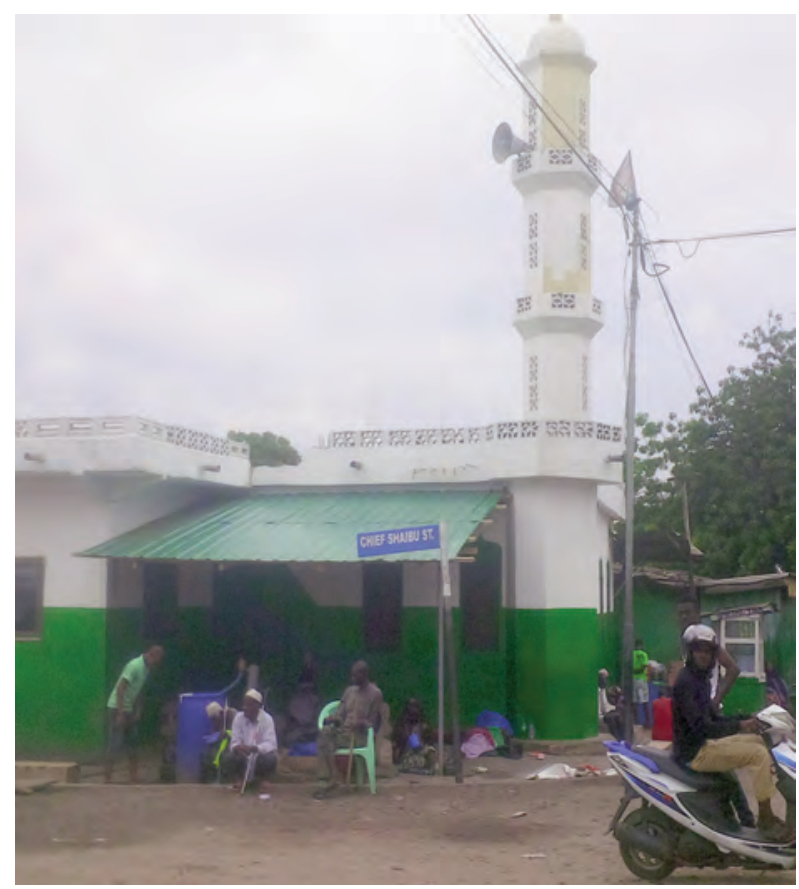

Figure 6. Religion and places of worship, such as the mosque depicted here, were for many young participants important vehicles for meaning and belonging. (Source: participant).

Evidently, this is problematic for those excluded from its membership and political participation, and in essence, generates young people's sense of marginalization. Despite belonging being connected to new modes of collectivity based on shared experience, interest and attachments (PFAFF-CZARNECKA, 2011), most dominant groups define notions of belonging in terms of "sameness", paving the way for discourses and practices of exclusion (ANTONSICH, 2010).

In Ga Mashie, the participants' photographs reflected a strikingly higher variety in topics that inspired a sense of belonging: cultural signifiers, local customs or traditional family lineage; unique features, 
both physical landmarks (e.g., James Town lighthouse) and intangible elements (e.g., boxing or fishing) that contribute to the identity of the area; and attractive or restorative places and hangout spots (e.g., the beach or a favorite bar) were cited as defining connections to place. In this respect, a sense of belonging is demonstrated as plural, fluid and often hybrid - constituted by various objects and processes of attachment - in the sheer diversity and richness of narratives between the case areas, and between or within individual narratives.

Findings suggest that most youth, despite experiencing significant forms of marginalization from spaces of power and labor, often connect to the community and to place in positive and meaningful ways. Some experience a deep sense of belonging in place, but the relations with the community are complex and often problematic. The prevailing sentiment seems to be one of only partial belonging to place, often accompanied by a longing for an imagined elsewhere. In order to generate a full sense of belonging in place, young people should feel free to express their identities, feel appreciated and taken seriously by, and be able to contribute to, the community and place (ANTONSICH, 2010). Many participants reported the sense of being powerless, having little or no voice in decision making that affects them, with a full sense of belonging seems to be out of reach.

\section{CONCLUSION}

This paper demonstrated that auto-photography manifests the potential to open a window into otherwise difficult to reach accounts of belonging and place, and is suitable for - yet by no means restricted to implementation in an African urban context. It is imperative that participatory methods are used reflexively and are adapted with sensitivity to the particular constellations of power within the socio-spatial context. In essence, these methods can reveal experiences of belonging and exclusion that are often oversimplified, ignored or suppressed by political schemes and formal narratives. The paper explored young people's experiences of marginalization, and the spatial and temporal tactics they adopt and adapt to challenge power relations and negotiate the urban environment of Accra. It also revealed that many young people have positive and meaningful connections to collectives and to place, but that these relationships are complex and often not unproblematic. The prevailing sentiment seems to be one of only partial belonging to place, alongside an intense longing for an imagined elsewhere. Many of them reported a sense of being powerless, having little or no voice in decision making that affects them, rendering the impossibility of a full sense of belonging.

The paper discloses that more empirical and theoretical research on the topic is urgently needed. To support further investigation, it concludes with key recommendations. A modest attempt was made to contribute to the ongoing project of further theorizing and explicitly spatializing the concept of belonging, in order to render it more useful for addressing discourses of spatial justice, but much more can be done. Likewise, effective guidelines should be developed for urban design and urban management that embrace participatory approaches of knowledge acquisition and production, while aiming towards inclusive urban environments that engage youth and other marginalized groups.

Fundamental to the understanding of voices of marginalized groups is the development of progressive modes of designing and managing public space that contribute to processes of sustainable urban development, especially from a social perspective. To produce inclusive urban environments that cater for all, and allow for differences and belonging, urban professionals and public officials need to engage genvinely with the users and the various polities and projects that constitute the city and come to terms with the everyday practices and senses of belonging in place. The current period, characterized by increasing mobility and transnational migration, has made narratives of belonging more relevant than ever. 


\section{REFERENCES}

ACCRA METROPOLITAN ASSEMBLY (2000) Age-Sex Structure of the Accra Metropolitan Assembly. Available at: http://ama.ghanadistricts.gov.gh (Accessed: 4 January 2015)

AGYEI-MENSAH, S. and OWUSU, G. (2010) Segregated by neighbourhoods? A portrait of ethnic diversity in the neighbourhoods of the Accra Metropolitan Area, Ghana, Population, Space and Place, 16 (May 2009), 499-516

ANDERSON, J. and JONES, K. (2009) The difference that place makes to methodology: uncovering the "lived space" of young people's spatial practices, Children's Geographies, 7(3), 291-303

ANTONSICH, M. (2010) In search of belonging: an analytical framework, Geography Compass, 4(6), 644-659

ARNOT, M. and SWARTZ, S. (2012) Youth citizenship and the politics of belonging: Introducing contexts, voices, imaginarie, Comparative Education, 48(1), 1-10

BEEHNER, L. (2007) The Effects of "Youth Bulge" on Civil Conflicts, Council on Foreign Relations, 27 April, 1-5. Available at: http://www.cfr.org/world/effects-youth-bulge-civilconflicts/p13093

DE BOECK, F. AND HONWANA, A. (2005) Children and Youth in Africa: Agency, Identity, and Place, Makers and Breakers. Children and Youth in Postcolonial Africa, 1-19

BOLLNOW, O. F. (1961) Lived-Space, Philosophy Today, 5(1), $31-39$

COHEN, B. (2006) Urbanization in developing countries: Current trends, future projections, and key challenges for sustainability, Technology in Society, 28(1-2), 63-80

CROWLEY, J. (1999) The politics of belonging: some theoretical considerations, In: The politics of belonging: Migrants and minorities in contemporary Europe. Ashgate Aldershot, UK, 15-41

DIOUF, M. (2003) Engaging Postcolonial Cultures: African Youth and Public Space, African Studies Review, 46(2), 1-12

EASTHOPE, H. (2009) Fixed Identities in a Mobile World? the Relationship Between Mobility, Place, and Identity, Identities, 6182

ELDEN, S. (2004) Understanding Henri Lefebvre: Theory and the Possible, Capital \& Class. London, Continuum

FENSTER, T. (2005) Gender and the city: the different formations of belonging, in Nelson, L. and Seager, J. (eds) A companion to feminist geography. Oxford, Blackwell, 242-257

FREEMAN, C. and TRANTER, P. J. (2011) Children and their urban environment: Changing worlds. London, Routledge

GHANA STATISTICAL SERVICES (2010) Demographic data on James Town, Ussher Town and Sabon Zongo based on 2010 Census. Accra: GSS

GOUGH, K. and FRANCH, M. (2005) Spaces of the street: Socio-spatial mobility and exclusion of youth in Recife, Children's Geographies, 3, 149-166

HARVEY, D. (1990) The Conditions of Postmodernity: An Enquiry into the Origins of Cultural Change. New York, Blackwell Publishing

HARVEY, D. (2003) Debates and Developments: The Right to the
City, International Journal of Urban and Regional Research, 27(December), 939-41

HOPKINS, P. E. (2010) Young People, Place and Identity. Milton, Routledge

KOHN, M. (2004) Brave New Neighbourhoods: The Privatization of Public Space. New York, Routledge

LÄHDESMÄKI, T. et al. (2016) Fluidity and flexibility of "belonging": Uses of the concept in contemporary research, Acta Sociologica, 59(3), 233-247

LANGEVANG, T. (2008a) Claiming place: The production of young men's street meeting places in Accra, Ghana', Geografiska Annaler, Series B: Human Geography, 90(3), 227-242

LANGEVANG, T. (2008b) "We are managing!" Uncertain paths to respectable adulthoods in Accra, Ghana', Geoforum. Elsevier Ltd, 39(6), 2039-2047

LANGEVANG, T. and GOUGH, K. V. (2009) Surviving through movement: the mobility of urban youth in Ghana, Social \& Cultural Geography, 10(January 2015), 741-756

LATHAM, A. (2003) Research, performance, and doing human geography: Some reflections on the diary-photograph, diary- interview method, Environment and Planning A, 35, 1993-2007

LEFEBVRE, H. (1991) The Production of Space. 1974th edn. Edited by D. Nicholson Smith (Translator). Blackwell Publishing

LOMBARD, M. (2013) Using auto-photography to understand place: reflections from research in urban informal settlements in Mexico, Area, 45(1), 23-32

LOMBARD, M. (2014) Constructing ordinary places: Place-making in urban informal settlements in Mexico, Progress in Planning. Elsevier Ltd, 94, 1-53

MELARA ARGUELLO, J. E. et al. (2013) Downgrading - An overlooked reality in African cities: Reflections from an indigenous neighborhood of Accra, Ghana, Applied Geography. Elsevier Ltd, $36,23-30$

PELLOW, D. (1991) The Power of Space in the Evolution of an Accra Zongo, Ethnohistory, 38(4), 414-450

PFAFF-CZARNECKA, J. (2011) From "identity" to "belonging" in social research: Plurality, social boundaries, and the politics of the self, Working Papers in Development Sociology and Social Anthropology, Universität Bielefeld, (368), 1-18

PIETERSE, E. (2011) Introduction: Rogue Urbanisms, Social Dynamics, 37(1), 1-4

RELPH, E. (1976) Place and Placelessness. London, Pion

ROBINSON, J. (2006) Ordinary Cities. New York, Routledge

SIMONE, A. (2003) For the City Yet to Come: Remaking Urban Life in Africa, in Mapping Africa by CCCB (Centre of Contemporary Culture of Barcelona)

SKELTON, T. and GOUGH, K. V. (2013) Introduction: Young People's Im/Mobile Urban Geographies', Urban Studies, 50(3), 455-466

SOJA, E. W. (1996) Thirdspace: Journeys to Los Angeles and Other Real-and Imagined Places. Oxford, Blackwell Publishers

TRUDEAU, D. (2006) Politics of belonging in the construction of 
landscapes: place-making, boundary-drawing and exclusion,

Cultural Geographies, 13(3), 421-443

TUAN, Y.-F. (1977) Space and Place: Humanistic Perspective, In:

S. Gale and G. Olsson (eds) Philosophy in Geography. Dordrecht,

Boston, London: D. Reidel Publishing company, 387-427

URDAL, H. (2011) A clash of generations? Youth bulges and political violence, in Paper presented at the United Nations expert group meeting on adolescents, youth and development, 21-22, July, New York

WIEDMANN, F., SALAMA, A. M. and MIRINCHEVA, V. (2014) Sustainable urban qualities in the emerging city of Doha, Journal of Urbanism: International Research on Placemaking and Urban Sustainability. Routledge, 7(1), 62-84

WINTON, A. (2005) Youth, gangs and violence: Analysing the social and spatial mobility of young people in Guatemala City, Children's Geographies, 3(2), 167-184

WORTH, S. (1964) Public administration and documentary film, Journal of Municipal Association for Management and Administration, 1, 9-25

YOUTH EMPLOYMENT NETWORK (2002) Ghana Country Report on Youth Employment - Prepared for the Youth Employment Summit (YES 2002)

YUVAL-DAVIS, N. (2006) Belonging and the politics of belonging, Patterns of Prejudice, 40(3), 197-214

ZHANG, Z. (2006) What Is Lived Space?, Ephemera: Theory \& Politics in Organization, 6(2), 219-223

ZILLER, R. C. and RORER, B. A. (1985) Shyness-environment interaction: A view from the shy side through auto-photography, Journal of Personality, 53(4), 626-639

Authors

Kristijn van Riel

PhD Candidate

Cluster for Research in Architecture and Urbanism in the Global South

Department of Architecture, University of Strathclyde, Glasgow, UK

kristijn.van-riel@strath.ac.uk

\footnotetext{
Ashraf M. Salama

Professor of Architecture and Head of Department Cluster for Research in Architecture and Urbanism in the Global South Department of Architecture, University of Strathclyde, Glasgow, UK ashraf.salama@strath.ac.uk
} 